\title{
Leveraging trade opportunities with non-traditional partners: the Malaysia-GCC perspective
}

\begin{abstract}
This paper examines the impact of economic factors on bilateral trade flows between Malaysia and the GCC through estimations of panel data using a gravity model. In particular, the paper compares the determinants of bilateral trade and trade potentials between Malaysia and two regions, the non-traditional Gulf alliance and the traditional ASEAN counterpart, to provide insights for leveraging opportunities through trade with the former. The gravity estimates imply the importance of size effects, similarities in GDP and differences in factor endowments as drivers of trade flows between Malaysia and the GCC, underlying the fact that inter-industry trade dominates these flows. The opposite holds in the case for the Malaysiaï ASEAN trade. Though export potentials for industrial products per se appear exhausted in trade with both regions, the Gulf region provides opportunities for Malaysia to export quantity-based final (end-use) products and to diversify its exporting strategy away from quality-based parts and components.
\end{abstract}

Keyword: Trade structure; Inter-industry trade; Panel gravity; GCC; Malaysia 